\title{
Emotional Intelligence and Employees' Innovator Role: The Moderating Effect of Service Types
}

\author{
Abdul Kadir Othman \\ Faculty of Office Management and Technology, Universiti Teknologi MARA Puncak Alam \\ 42300 Puncak Alam, Selangor, Malaysia \\ Tel: 60-3-3258-5006 E-mail: abdkadir@salam.uitm.edu.my
}

Received: May 27, $2011 \quad$ Accepted: June 14, $2011 \quad$ Published: October 1, 2011

doi:10.5539/ass.v7n10p151 URL: http://dx.doi.org/10.5539/ass.v7n10p151

\begin{abstract}
Services vary significantly. Some services require high level of customization while others are focusing on standardization as the main objective. Customized services absolutely require service providers' creativity in meeting the customers' expectation. Studies have shown that Emotional Intelligence (EI) can be used to enhance service providers' innovator role. Therefore, this study aims at investigating the moderating effect of service types on the relationship between EI factors (self emotional appraisal, others' emotional appraisal, regulation of emotion, and use of emotion) and employees' innovator role. Analyses of 167 responses revealed that the differential slopes of the moderator-based subgroups for the relationship between self emotional appraisal (SEA) and innovator role were significant. The findings highlight the importance of EI for employees in different service types to enhance their innovator role.
\end{abstract}

Keywords: Emotional intelligence, Innovation, Service types, Professional service, Service shop, Mass service

\section{Introduction}

Customer satisfaction depends mostly on successful service delivery, which in turn relies on employees' capability to work effectively. One aspect of work effectiveness is the ability to be creative and innovative. Creativity is crucial to organizations because if they intend to remain competitive in a complex and changing environment, they must hire the employees who are not only creative in their jobs but also contribute to the effectiveness and adaptability of the organizations as a whole (Schein, 1980). Thompson and Werner (1997) asserted that "in most organizations, it is no longer sufficient for an employee simply to carry out his or her essential job functions. Employees today are expected to take initiative and engage in those behaviors which insure that the organization's goals are realized. Moreover, the rapid pace of change in many industries today has made the "job descriptions" per se somewhat obsolete".

Defined as a set of abilities to perceive accurately, appraise, and express emotion; the ability to access and/or generate feelings when they facilitate thought; the ability to understand emotion and emotional knowledge; and the ability to regulate emotions to promote emotional and intellectual growth (Mayer \& Salovey, 1997), EI has been shown to be related to innovation and creativity (Stough \& De Guara, 2003; Suliman \& Al-Shaikh, 2006). Employees with high EI tend to be innovative since they are able to identify, understand, manage and use negative or positive feelings by finding associations among available elements to find novel and creative solution to the problem at hand. However, the relationship between EI and innovator role is believed to be influenced by type of services the employees are working. Thus, this paper is meant to investigate the role played by service types (professional service, service shop and mass service) on the relationships between the EI abilities and innovator role.

\section{Previous Research}

Innovator role is defined as creativity and innovation in one's job and the organization as a whole (Welbourne, Johnson, \& Erez, 1998). Creativity, on the other hand, is defined as "the product of novel and useful ideas" (George \& Zhou, 2002; Madjar, Oldham, \& Pratt, 2002). If organizations intend to remain competitive in a complex and changing environment, they must have employees who are not only creative in their jobs but also contributive to the effectiveness and adaptability of the organizations as a whole (Schein, 1980). In today's 
organizations, simply carrying out his or her essential job functions is no longer adequate since the employee is expected to take initiative and engage in behaviors that insure the realization of the organization's goals (Thompson \& Werner, 1997).

Creative ideas are produced when employees are able to identify relationships or associations of elements that others did not see. "When employees are demonstrating an increased sensitivity for recognizing unusual associations, they may be particularly valuable assets to help organizations improved their creative performance" (Fong, 2006). Innovation or creativity is not a straight forward process. According to Easterby-Smith, Crossan and Niccolini (2000), innovative learning is obviously complex, involving a mix of rational, intuitive, emotional, and social processes. Similarly, Fenwick (2003) found that emotion plays an important role in employees' readiness to create and innovate.

Several studies have explored the role of affect in influencing creativity at work. Amabile, Barsade, Mueller and Staw (2005) found that positive affects relate positively to creativity in organizations in a simple linear fashion. Fong (2006) claimed that individuals experiencing emotional ambivalence are better at recognizing unusual relationships between constructs, therefore showing an ability to be important to organizational creativity. Besides, research has also established that positive mood or affect facilitates problem solving (Mayer \& Salovey, 1990). This is because positive affects lead to cognitive variation that stimulates creativity. Frederickson (1998) stated that positive emotions broaden the scope of attention and the scope of cognition. Fredrickson (2001) argued that people see positive emotions as a signal by being more exploratory and playful, thus allowing their minds to become more creative. She noted that "experiences of certain positive emotions prompt individuals to discard time-tested or automatic (everyday) behavioral scripts and to pursue novel, creative, and often unscripted paths of thought and action" (Fredrickson, 1998).

Studies have also shown that EI is related to innovation and creativity. Those having high EI abilities tend to be innovative and creative (Suliman \& Al-Shaikh, 2006). Emotionally intelligent employees are able to identify their true feelings, understand the causes and consequences of the feelings, and manage as well as use the feelings to find creative solutions for the existing problems. Stough and De Guara (2003) found that subordinates' emotional recognition and expression (in oneself), emotion management and understanding emotions external, components of EI as measured by the SUEIT were positively related to the ability to be innovative and creative in the workplace.

Employees with high EI will engage in high innovator role but employees with low EI will result with low innovator role. Emotionally intelligent employees are able to identify, understand, manage and use negative or positive feelings by the way of finding associations among available elements to find novel and creative solution to the existing problems. The relationships, nonetheless, are moderated by service types in which the employees are working. Services can be divided into three different types; professional service, service shop, and mass service, based on six dimensions; people versus equipment, level of customization, extent of employee/customer contact, level of employee discretion, value added in back office versus front office, and product versus process focus (Silvestro, Fitzgerald, Johnson \& Voss, 1992).

In professional service, employees are offering customized services which require them to use high level of discretion and judgment. Employees' creativity and innovation in their job are highly appreciated in attending to the customers' needs and concern. Therefore, EI in professional service can enhance the employees' innovative role to provide creative solutions to customers by identifying the emotions of self and others, regulating those emotions and using the emotions to achieve the desired results. For example, lawyers need to assess the jury and the judge's emotional states before they can develop creative and innovative approaches to win the heart and mind of the jury as well as the judge.

In service shop, the need for EI is lesser compared to professional service. Complying with the job requirements and using little discretion and judgment are expected from the employees. Bank tellers for example, in dealing with customers' loan application can use their discretion when suggesting amount that can be approved, mortgages needed, and period of repayment. However, their role is restricted to the established rules. The application of EI during the process is moderately required to provide creative solution to the customer's need because of the limited space to exercise personal discretion and judgment. In mass service, since the services offered are standardized, routine and with minimum level of interaction with the customers, the use of EI is limited due to the nature of work performed. Employees in fast food restaurants, for example, are working in accordance to the established standard operating procedures with little interaction with the customers. Deviation from the procedures is not tolerated therefore, the need for EI to facilitate employees' innovator role is minimum in mass service. 


\section{Hypotheses}

Based on the discussion regarding the moderating effect of service types on the relationship between EI and innovator role and, the following hypotheses are suggested:

H1: Service types moderate the relationship between self emotional appraisal and innovator role

H2: Service types moderate the relationship between others' emotional appraisal and innovator role

H3: Service types moderate the relationship between regulation of emotion and innovator role

H4: Service types moderate the relationship between use of emotion and innovator role

\section{Research Method}

\subsection{Research Instrument}

Employees' EI was measured by using a 16 items self-rated EI scale developed by Wong and Law (2002) (WLEIS). This scale is based on Mayer and Salovey's (1990) original conceptualization of EI. Besides, previous studies support the scale's factor structure, internal consistency, convergent, and discriminant validity (Law, Wong, \& Song, 2004; Sy, Tram, \& O' Hara, 2006; Wong \& Law, 2002). The conceptual definition of WLEIS is as follows:

1. Self emotional appraisal (SEA) - the individual's ability to understand their deep emotions and be able to express these emotions naturally. A sample item is "I have a good sense of why I have certain feelings most of the time".

2. Others' emotional appraisal (OEA) - the ability to perceive and understand the emotions of those people around them. A sample item is "I always know my friends' emotions from their behavior".

3. Regulation of emotion (ROE) - the ability of people to regulate their emotions, which will enable a more rapid recovery from psychological distress. A sample item is "I am able to control my temper so that I can handle difficulties rationally".

4. Use of emotion (UOE) - the ability of individuals to make use of their emotions by directing them towards constructive activities and personal performance. A sample item is "I always set my goals for my self and then try my best to achieve them".

Each item is rated on a 7-point scale ranging from 1 (totally disagree) to 7 (totally agree). The original authors have reported that the reliability estimates (coefficient alphas) for the four dimensions of self-emotion appraisal, others-emotion appraisal, regulation of emotion and use of emotion were $.89, .85, .76$, and .88 , respectively. In this study, the reliability estimates for the four dimensions of EI were $.90, .89, .92$, and .89 , respectively. Innovator role measure was derived from Welbourne, Johnson and Erez's (1998) Role Based Performance Scale (RBPS), which comprises four items. The assessment of employees' innovator role was performed by their peers in order to avoid measurement bias (Podsakoff, MacKenzie, Lee, \& Podsakoff, 2003). A sample item for innovator role is "Coming up with new ideas". Each item was rated on a 5-point scale ranging from 1 (needs much improvement) to 5 (excellent). In this study, the reliability estimate for the factor was 0.91 .

Service process choice questionnaire developed by Collier and Meyer (2000) was used to verify the service classification as proposed by Silvestro et al. (1992). The five-item scale serves as a tool to see whether service companies fall into their respective three categories or otherwise. An example of the item is "how much customization does the service provider offer for the most common service?" The response alternatives range from 1 for no customization to 10 for total customization. The demographic variables, which comprise respondent's age, gender, marital status, job position, job experience and education, were controlled so that the observed associations were not spuriously caused by these variables (Lopes, Grewal, Kadis, Gall, \& Salovey, 2006) and to rule out an alternative explanation of any results (Côté \& Miners, 2006).

\subsection{Research Sample}

A total of 400 questionnaires were distributed to service employees attached to 40 service companies located in Selangor and Kuala Lumpur. Questionnaires were distributed through the human resources managers of each participating company. They were initially explained to randomly distribute the questionnaires to their respective employees (self-selected respondents) (Bhaskaran \& Sukumaran, 2007). The process of questionnaires distribution and collection took approximately six months. Out of 400 questionnaires distributed, a total of 188 were returned, yielding a response rate of $47 \%$, which is consistent with the average response rate as suggested by Baruch and Holtom (2008). From the 188 returned questionnaires, 19 responses were found to be non-usable. Given that these responses were either incomplete or completed by inappropriate individuals; the 19 responses were excluded from subsequent data analyses. Thus, only 167 questionnaires $(41.75 \%)$ were coded and analyzed. 


\section{Data Analysis}

\subsection{Profile of Firms (A Priori vs. a Posterior Classification)}

Based on the service classification theory, the original numbers of respondents for professional service, service shop and mass service were 52,50 and 53 , respectively. The theory-based classifications were tested to ensure that they truly reflect the actual data. Therefore, cluster analysis was conducted to verify the respondents' groupings as suggested by the theory by using the responses from the five statements in the questionnaire. These statements measure the extent to which the services are dependent on people versus equipment, customization versus standardization, extent of employee/customer contact, level of employee discretion, value added in back office versus front office, and product versus process. The results of cluster analysis reveal that the numbers of respondents changed to be 48 for professional service, 56 for service shop and 52 for mass service, which amounted to 155 . For 12 cases which were incomplete, the original classifications were use to classify them. Table 1 presents the cross-tabulation of cases based on the original and new classifications of service.

The empirically determined classifications were used in the subsequent data analysis since they were empirically supported. Theoretically, service positioning matrix provides a clear guideline on how service companies can be grouped. However, in reality, there is no clear distinction among service companies since they are using a varying combination of service classification dimensions. For example, in a service company alone, there are different emphases on service; some employees are given a great extent of autonomy to use their discretion when dealing with customers but the others are required to strictly follow the standard procedures. Therefore, the empirically determined classifications are the best to represent different types of service.

\subsection{Reliability and Correlation Analysis}

The reliability analysis was conducted by computing the Cronbach's alpha for each measure. The reliability of a measure indicates the stability and consistency of the instrument in measuring a concept and helps to assess the goodness of a measure (Sekaran, 2000). It is suggested that the minimum acceptable reliability be set at .60. The Cronbach's alphas for independent variables are in the range of .89 to .92 , and 0.91 for the dependent variable, indicating that the measures have high internal consistency exceeding Nunnally's (1978) threshold of .70. As indicated in Table 4, all EI variables were moderately correlated with each other, suggesting a convergent validity. However, some EI variables were not significantly correlated with the work effectiveness variables. Although they were insignificantly correlated, the variables were also submitted for subsequent analyses in order to see the interaction effects between independent and moderating variables and their influence on the dependent variables. The results of correlation analysis are presented in Table 2.

\section{Hypotheses Testing}

The effects of the moderating variables were examined by utilizing a series of four-step hierarchical regression analyses. Before conducting the analyses, homogeneity of error variance components for each relationship between the independent and dependent variables for the three groups of services were determined by using Alternative Tests for Moderated Multiple Regression (ALTMMR) (Aguinis, 2004), which can be reached at $\mathrm{http}: / / \mathrm{www} . c u d e n v e r . e d u / \sim$ haguinis/mmr/. DeShon \& Alexander's rule of thumb for homogeneity (based on error variance ratio, which should be less than 1:1.5) and Bartlett's test were used to determine the homogeneity or heterogeneity of error variance. The results of DeShon \& Alexander's rule of thumb for homogeneity revealed that all group variances met the homogeneity assumption. Similarly, the results of ALTMMR (Bartlett's tests) confirm the homogeneity of error variance of the moderator-based subgroups for the relationships between EI and innovator role (SEA and innovator role $(\mathrm{M}=0.06, p=0.97)$, OEA and innovator role $(\mathrm{M}=0.14, p=0.93), \mathrm{ROE}$ and innovator role $(\mathrm{M}=0.03, p=0.99)$, $\mathrm{UOE}$ and innovator role $(\mathrm{M}=0.07, p=0.96))$. As a result, the regression analysis can be subsequently performed.

The regression analysis was carried out by first entering control variables, second, the independent variables, third, the moderator, and fourth, the interaction terms of the independent and moderator variables, into the regression equation. There is an interaction effect if the interaction term is significant, and the increment in total variance explained, or $R^{2}$, is also significant as indicated by the $F$ statistics (Hair, Black, Babin, Anderson, \& Tatham, 2006). Table 3 summarizes the results of multiple hierarchical regression analyses, which indicate that all moderating variables (service shop and mass service) were not significantly different from the reference variable (professional service) to influence or moderate the relationships between EI and innovator role.

However, to verify the findings, the Alternative Tests for Moderated Multiple Regression (ALTMMR) (Aguinis, 2004) were conducted. James's and Alexander's tests show that that there was an evidence of differential slopes among moderators for the relationship between SEA and innovator role $(\mathrm{U}=8.39$ and $\mathrm{U}$ (Critical) $=6.21 ; \mathrm{A}=7.93$, 
$p=0.02$ ), indicating that service types significantly moderate the relationship. There was no evidence of differential slopes for other relationships between EI and innovator role (OEA and innovator role ( $U=1.70$ and $U$ $($ Critical $)=6.21 ; \mathrm{A}=1.67, p=0.43), \mathrm{ROE}$ and innovator role $(\mathrm{U}=2.34$ and $\mathrm{U}$ (Critical) $=6.21 ; \mathrm{A}=2.29, p=0.32)$, $\mathrm{UOE}$ and innovator role $(\mathrm{U}=1.77$ and $\mathrm{U}($ Critical $)=6.21 ; \mathrm{A}=1.74, p=0.42)$.

To sum up, the hierarchical regression analysis did not significantly discover the influence of service types on the relationships between EI and peer's evaluations of service provider's innovator role. However, James's and Alexander's tests significantly identify the differential slopes of the moderator-based subgroups on one relationship; between self emotional appraisal (SEA) and innovator role. Therefore, it can be concluded that service types significantly moderate the relationships between SEA and innovator role. Therefore, hypotheses 1 is supported while hypotheses 2 through 4 are not supported due to insufficient evidence.

\section{The Moderating Effects of Service Types on the Relationships between Emotional Intelligence and} Work Effectiveness

Based on the results of James's and Alexander's tests, the differential slopes of the moderator-based subgroups for the relationship between SEA and innovator role were significant. The graphical illustration was drawn to portray the significant interactions more clearly. Drawing the graph, SEA was first recoded into three categories, respectively; Low, Moderate and High by dividing the respondents into three approximately equal groups using percentile $(0-33$ percent $=$ Low, $33.1-66$ percent $=$ Moderate, and $66.1-100$ percent $=$ High $)$. The results of the significant interactions are presented in Figure 1.

At the low level of SEA, professional service employees received higher peer's evaluation on innovator role compared to those in service shop and mass service. The ratings for the employees from the three types of service improved notably with the increment in the SEA ability from low to moderate level especially for those in service shop and mass service. However, at the high level of SEA, the ratings received by professional service and service shop employees considerably dropped. For mass service employees the ratings kept on escalating. The findings highlight that professional service and service shop employees can achieve outstanding innovator role when they are equipped with the moderate level of SEA. However, mass service employees can optimize their innovator role effectiveness when they are equipped with high level of SEA.

A number of studies have fairly established that emotion plays an important role in employees' readiness to be creative and innovative (Amabile et al., 2005; Fenwick, 2003; Fong, 2006; Fredrickson, 1998, 2001; Park, 2005). Several studies have shown that EI is related to innovation and creativity (Stough \& De Guara, 2003; Suliman \& Al-Shaikh, 2006). Employees with high EI will engage in high innovator role but employees with low EI will perform low innovator role. Emotionally intelligent employees are able to identify, understand, manage and use negative or positive feelings by the way of finding associations among available elements to find novel and creative solution to the problems at hand. This study has discovered that the relationship between EI and innovation is moderated by service types. Moderate EI is required for professional and service shop employees and high $\mathrm{EI}$ is required for mass service employees.

Professional service is associated with high customization, high service provider-customer interaction, and high discretion required from service providers; therefore, innovation and creativity are highly required. This association explains why although at the low level of SEA, professional service employees were highly evaluated by their peers on their innovator role. Perhaps, these employees are professional, highly qualified and well-trained to execute their tasks effectively; hence, they can utilize other abilities, such as cognitive ability to achieve outstanding innovator role. However, when they are equipped with high EI, their innovator role decreases because high SEA will lead them to engage in excessive self-assessment, questioning their actions (e.g. Why should I do this while others don't even bother), which subsequently reduces the employees' willingness to be innovative. Therefore, employees in professional service require moderate level of EI to be effective at their innovator role.

Service shop is described as being in the middle between professional service and mass service. Services offered are moderately customized with moderate level of service provider-customer interaction and moderate discretion exercised by the employees. From figure 1, the effect of service shop on the relationship is more or less similar to the effect of mass service at the low and moderate levels of SEA. However, the high level of SEA, the ratings received by service shop employees dropped significantly indicating that high EI will negatively affect their innovator role. Similar to professional service employees, high dose of EI will make the employees to engage in excessive self-assessment, questioning their actions that subsequently affect their innovator role. Therefore, employees in service shop require moderate level of SEA to be innovative.

Employees in mass service are supposed to find little utility of EI. However, the study proves that high SEA 
ability facilitates employees' innovator role. Working in a confined environment, complying with the job requirements and using little discretion and judgment during service delivery may create unfavorable emotional states. When equipped with high SEA, the employees are able to accurately identify and understand their emotions as well as to understand the reasons and consequences of having those emotions; therefore, motivates them to be innovative.

Innovation is perceived differently in mass service as employees may be allowed to be innovative in areas that are outside the established processes. Employees in fast food restaurants, for example, are working in accordance to the established standard operating procedures (SOP) or the established rules (Brotheridge \& Grandey, 2002; Hochschild, 1983; Wharton, 1999) with little interaction with the customers. Deviation from the procedures is not tolerated since it may affect the quality of service delivered. However, the employees are given the opportunity to be innovative in sub processes such as decorating the premises, arranging table settings, and others. Hence, mass service employees can optimize their innovator role when they are equipped with high level of SEA most probably due to the nature of their work. Working in a confined environment, complying with the stringent job requirements and using little discretion and judgment during service delivery, being innovative and creative is perceived as an exit route from stress and boredom.

The study also found that service types do not moderate the relationships of others' emotional appraisal (OEA), regulation of emotion (ROE), and use of emotion (UOE) with innovator role. These findings indicate that these three factors play similar roles in influencing service employees' innovator role regardless of the types of service they are offering. Based on the results of the regression analysis, the three factors are not significant to influence employees' innovator role, indicating that in Malaysian service environment, OEA, ROE and UOE do not contribute to the enhancement of employees' innovator role most probably due to organizational culture which also reflects the national culture. Malaysians are considered to be high power distance, moderate uncertainty avoidance, high collectivism and moderate masculinity (Hofstede, 2001). They are more emotional and motivated by inner nervous force. However, they tend to keep their emotion to themselves due to face saving relationship maintenance. This practice explains why OEA, ROE and UOE do not significantly influence employees' innovator role in service businesses.

\section{Summary and Concluding Remarks}

Providing excellent services to the customer require service to be innovative and creative. Research has established that EI can be used to enhance employees' creativity. However, in the present study, it was found that professional service and service shop employees need a moderate level of self emotional appraisal (SEA) ability in order to achieve high innovator role effectiveness. High level of SEA reduces their capacity to be innovative since high SEA ability may result in the employees being too sensitive and attentive to their feelings and emotions to focus on their innovator role. However, mass service employees can optimize their innovator role when they are equipped with high level of SEA since this ability motivates them going beyond their prescribed duties being innovative on their job.

The analysis was conducted based on 167 data from various service organizations. Although measures were taken to ensure that the findings can be generalized across population, the sample size was too small to produce convincing results. Some hypotheses were not empirically supported due to insignificant results. These occurrences might for example just be due to a small sample size (Cozby, 1996). Another implication of small sample size, separate analysis based on service categories (professional service, service shop and mass service) as proposed by Silvestro et al. (1992) cannot be conducted. If the sample size is adequate (at least 100 responses for each service category to allow multivariate data analysis to be conducted), separate analysis (based on different types of service) could be carried out. Therefore, future study should consider the issue of sample size and incorporate separate analyses in accordance with service categories so that some of the study's variances can be justified by its design.

Service positioning matrix as proposed by Silvestro et al. (1992) provides a useful guideline to classify service into homogeneous groups. However, a service classification according to certain service themes, such as retail and corporate banking, could be misleading. A more accurate classification could be achieved if the consideration is made based on the job title of service providers. For example, marketing officer in corporate banking deals with high interaction with the customers, standardization and discretion. Bank officer in corporate banking, on the other hand, involves low to moderate interaction with the customers, service standardization and discretion. Although both officers work in the same business themes one officer offers service shop/professional service but another officer offers a service shop/mass service type of service. Therefore, a service classification in accordance with employees' job title might offer a more accurate service classification. 


\section{References}

Aguinis, H. (2004). Regression analysis for categorical moderators. New York: The Guilford Press.

Amabile, T. M., Barsade, S. G., Mueller, J. S., \& Staw, B. M. (2005). Affect and creativity at work. Administrative Science Quarterly, 50, 367-403. http://dx.doi.org/10.2189/asqu.2005.50.3.367

Baruch, Y., \& Holtom, B. C. (2008). Survey response rate levels and trends in organizational research. Human Relations, 61(8), 1139-1160. http://dx.doi.org/10.1177/0018726708094863

Bhaskaran, S., \& Sukumaran, N. (2007). National culture, business culture and management practices: Consequential relationships? Cross Cultural Management: An International Journal, 14(1), 54-67. http://dx.doi.org/10.1108/13527600710718831

Brotheridge, C. M., \& Grandey, A. A. (2002). Emotional labor and burnout: Comparing two perspectives of "people work". Journal of Vocational Behavior, 60, 17-39. http://dx.doi.org/10.1006/jvbe.2001.1815

Collier, D. \& Meyer, S. (2000). An empirical comparison of service matrices. International Journal of Operations and Production Management, 20(6), 705-729. http://dx.doi.org/10.1108/01443570010321685

Côté, S., \& Miners, C. T. H. (2006). Emotional intelligence, cognitive intelligence, and job performance. Administrative Science Quarterly, 51(1), 1-28. http://dx.doi.org/10.2189/asqu.51.1.1

Cozby, P. C. (1996). Methods in behavioral research (6 ed.). Mountain View: Mayfield Publishing Company.

Easterby-Smith, M., Crossan, M., \& Niccolini, D. (2000). Organizational learning: Debates past, present and future. Journal of Management Studies, 37(6), 783-796. http://dx.doi.org/10.1111/1467-6486.00203

Fenwick, T. (2003). Examining workplace learning in new enterprises. The Journal of Workplace Learning, 15(3), 123-132. http://dx.doi.org/10.1108/13665620310468469

Fong, C. T. (2006). The effects of emotional ambivalence on creativity. Academy of Management Journal, 49(5), 1015-1030. http://dx.doi.org/10.5465/AMJ.2006.22798182

Fredrickson, B. L. (1998). What good are positive emotions? Review of General Psychology, 2, 300-319. http://dx.doi.org/10.1037/1089-2680.2.3.300

Fredrickson, B. L. (2001). The role of positive emotions in positive psychology: The broaden-and-build theory of positive emotions. American Psychologist, 56, 218-226. http://dx.doi.org/10.1037/0003-066X.56.3.218

George, J. M., \& Zhou, J. (2002). Understanding when bad moods foster creativity and good ones don't: The role of context and clarity of feelings. Journal of Applied Psychology, 87(4), 687-697. http://dx.doi.org/10.1037/0021-9010.87.4.687

Hair, J. F. J., Black, W. C., Babin, B. J., Anderson, R., E., \& Tatham, R. L. (2006). Multivariate data analysis (6th ed.). New Jersey: Pearson Education, Inc.

Hochschild, A. R. (1983). The managed heart: Commercialization of human feelings. Berkeley: University of California Press.

Hofstede, G. (2001). Culture's Consequences, Comparing Values, Behaviors, Institutions, and Organizations Across Nations. Thousand Oaks CA: Sage Publications.

Law, K. S., Wong, C.-S., \& Song, L. J. (2004). The construct and criterion validity of emotional intelligence and its potential utility for management studies. Journal of Applied Psychology, 89(3), 483-496. http://dx.doi.org/10.1037/0021-9010.89.3.483

Lopes, P. N., Grewal, D., Kadis, J., Gall, M., \& Salovey, P. (2006). Evidence that emotional intelligence is related to job performance and affect and attitudes at work. Psicothema, 18(1), 132-138.

Madjar, N., Oldham, G. R., \& Pratt, M. G. (2002). There's no place like home? The contributions of work and nonwork creativity support to employees' creative performance. Academy of Management Journal, 45, 757-767. http://dx.doi.org/10.2307/3069309

Mayer, J. D., \& Salovey, P. (1990). Emotional intelligence. Imagination, Cognition and Personality, 9, 185-211. [Online]

http://baywood.metapress.com/openurl.asp?genre=article\&id=doi:10.2190/DUGG-P24E-52WK-6CDG

Mayer, J. D., \& Salovey, P. (1997). What is emotional intelligence? In P. Salovey \& D. Sluyter (Eds.), Emotional development and emotional intelligence: Education implication. New York: Basic Books.

Nunnally, J. C. (1978). Psychometric theory. New York: McGraw-Hill. 
Park, J. (2005). Fostering creativity and productivity through emotional literacy: The organizational context. Development and Learning in Organization, 19(4), 5-7. http://dx.doi.org/10.1108/14777280510606510

Podsakoff, P. M., MacKenzie, S., B., Lee, J.-Y., \& Podsakoff, N. P. (2003). Common method biases in behavioral research: A critical review of the literature and recommended remedies. Journal of Applied Psychology, 88(5), 879-903. http://dx.doi.org/10.1037/0021-9010.88.5.879

Schein, E. H. (1980). Organizational psychology (3 ed.). Englewood Cliffs, NJ: Prentice Hall.

Sekaran, U. (2000). Research methods for business: A skill-building approach (3 ed.). New York: John Wiley \& Sons, Inc.

Silvestro, R., Fitzgerald, L., Johnson, R., \& Voss, C. (1992). Towards a classification of service processes. International Journal of Service Industry Management, $3(3), \quad 62-76$. http://dx.doi.org/10.1108/09564239210015175

Stough, C., \& De Guara, D. (2003). Examining the relationship between emotional intelligence and job performance. Australian Journal of Psychology, 55, 145.

Suliman, A. M., \& Al-Shaikh, F. N. (2006). Emotional intelligence at work: Links to conflict and innovation. Employee Relations, 29(2), 208-220. http://dx.doi.org/10.1108/01425450710720020

Sy, T., Tram, S., \& O' Hara, L. A. (2006). Relation of employee and manager emotional intelligence to job satisfaction and performance. Journal of Vocational Behavior 68(3), 461-473. http://dx.doi.org/10.1016/j.jvb.2005.10.003

Thompson, H., \& Werner, J. (1997). The impact of role conflict/facilitation on core and discretionary behaviors: Testing a mediated model. Journal of Management, 23(4), 583-601. http://dx.doi.org/10.1177/014920639702300405

Welbourne, T. M., Johnson, D. E., \& Erez, A. (1998). The role-based performance scale: Validity analysis of a theory-based measure. Academy of Management Journal, 41(5), 540-555. http://dx.doi.org/10.2307/256941

Wharton, A. S. (1999). The psychosocial consequences of emotional labor. The ANNALS of the American Academy of Political and Social Science, 561(1), 158-176. http://dx.doi.org/10.1177/000271629956100111

Wong, C.-S., \& Law, K. S. (2002). The effects of leader and follower emotional intelligence on performance and attitude: An exploratory study. The Leadership Quarterly, 13(3), 243-274. http://dx.doi.org/10.1016/S1048-9843(02)00099-1

Table 1. Cross-tabulation of Cluster Number of Case

\begin{tabular}{llrrr|r}
\hline & & \multicolumn{3}{c|}{ Cluster Number of Case } & \multicolumn{1}{c}{ Total } \\
\cline { 3 - 5 } Types & & Service Shop & Mass Service & Professional Service & \multicolumn{1}{c}{ Tount } \\
Professional & Count & 20 & 19 & 13 & 52 \\
Service & \% within type & $38.5 \%$ & $36.5 \%$ & $25.0 \%$ & $100.0 \%$ \\
& \% of Total & $12.9 \%$ & $12.3 \%$ & $8.4 \%$ & $33.5 \%$ \\
Service Shop & Count & 21 & 15 & 14 & 50 \\
& \% within type & $42.0 \%$ & $30.0 \%$ & $28.0 \%$ & $100.0 \%$ \\
& \% of Total & $13.5 \%$ & $9.7 \%$ & $9.0 \%$ & $32.3 \%$ \\
Mass Service & Count & 15 & 17 & 21 & 53 \\
& \% within type & $28.3 \%$ & $32.1 \%$ & $39.6 \%$ & $100.0 \%$ \\
& \% of Total & $9.7 \%$ & $11.0 \%$ & $13.5 \%$ & $34.2 \%$ \\
\hline Total & Count & 56 & 51 & 48 & 155 \\
& \% within type & $36.1 \%$ & $32.9 \%$ & $31.0 \%$ & $100.0 \%$ \\
& \% of Total & $36.1 \%$ & $32.9 \%$ & $31.0 \%$ & $100.0 \%$ \\
\hline
\end{tabular}


Table 2. Correlation Analysis

\begin{tabular}{llrrrrrrrl}
\hline No & Factors & Mean & SD & 1 & 2 & 3 & 4 & \\
\hline 1 & Self Emotional Appraisal & 5.51 & .93 & $(0.90)$ & & & & \\
2 & Others' Emotional Appraisal & 4.87 & .86 & $.514^{* *}$ & $(0.89)$ & & & \\
3 & Regulation of Emotion & 5.00 & .95 & $.301^{* *}$ & $.371^{* *}$ & $(0.92)$ & & \\
4 & Use of Emotion & 5.60 & .81 & $.498^{* *}$ & $.520^{* *}$ & $.475^{* *}$ & $(0.89)$ & \\
5 & Innovator role & 3.65 & .78 & $.183^{*}$ & $.218^{* *}$ & $.199^{* *}$ & $.202^{* *}$ & $(0.91)$ \\
\hline
\end{tabular}

Notes: ** Correlation is significant at the 0.01 level (2-tailed); $*$ Correlation is significant at the 0.05 level

(2-tailed); Cronbach's alpha reliability coefficients are along the diagonals in parentheses.

Table 3. Multiple regression results of Service Types as moderators in the relationships between EI and peer's evaluation of Innovator Role

\begin{tabular}{|c|c|c|c|}
\hline & $\begin{array}{c}\text { Model } 1 \\
\text { Std } \beta \\
\end{array}$ & $\begin{array}{c}\text { Model } 2 \\
\text { Std } \beta \\
\end{array}$ & $\begin{array}{c}\text { Model } 3 \\
\text { Std } \beta \\
\end{array}$ \\
\hline \multicolumn{4}{|l|}{ Model variables } \\
\hline Self Emotional Appraisal & .028 & .026 & .203 \\
\hline Others' Emotional Appraisal & .143 & .143 & -.095 \\
\hline Regulation Of Emotion & .109 & .114 & .198 \\
\hline Use of Emotion & .066 & .065 & .042 \\
\hline \multicolumn{4}{|l|}{ Moderating variables } \\
\hline Service Shop & & -.040 & -.022 \\
\hline Mass Service & & -.025 & -.024 \\
\hline \multicolumn{4}{|l|}{ Interaction terms } \\
\hline Self Emotional Appraisal x Service Shop & & & -.051 \\
\hline Others' Emotional Appraisal x Service Shop & & & .158 \\
\hline Regulation Of Emotion x Service Shop & & & .010 \\
\hline Use of Emotion x Service Shop & & & .059 \\
\hline Self Emotional Appraisal x Mass Service & & & $-.306^{* *}$ \\
\hline Others' Emotional Appraisal x Mass Service & & & $.227 *$ \\
\hline Regulation Of Emotion x Mass Service & & & -.090 \\
\hline Use of Emotion x Mass Service & & & .022 \\
\hline $\mathrm{R}^{2}$ & .133 & .134 & .199 \\
\hline Adjusted $\mathrm{R}^{2}$ & .059 & .048 & .070 \\
\hline $\mathrm{R}^{2}$ Change & .069 & .001 & .064 \\
\hline F Change & 3.053 & .113 & 1.437 \\
\hline Significance F Change & .019 & .893 & .186 \\
\hline Durbin-Watson & & & 1.982 \\
\hline
\end{tabular}

Notes: $* * *$ significance at the .01 level; $* *$ significance at the .05 level; $*$ significance at the .1 level; Dummy coded variables: Service types: 00 Professional Service, 01 Service Shop, 10 Mass Service. 


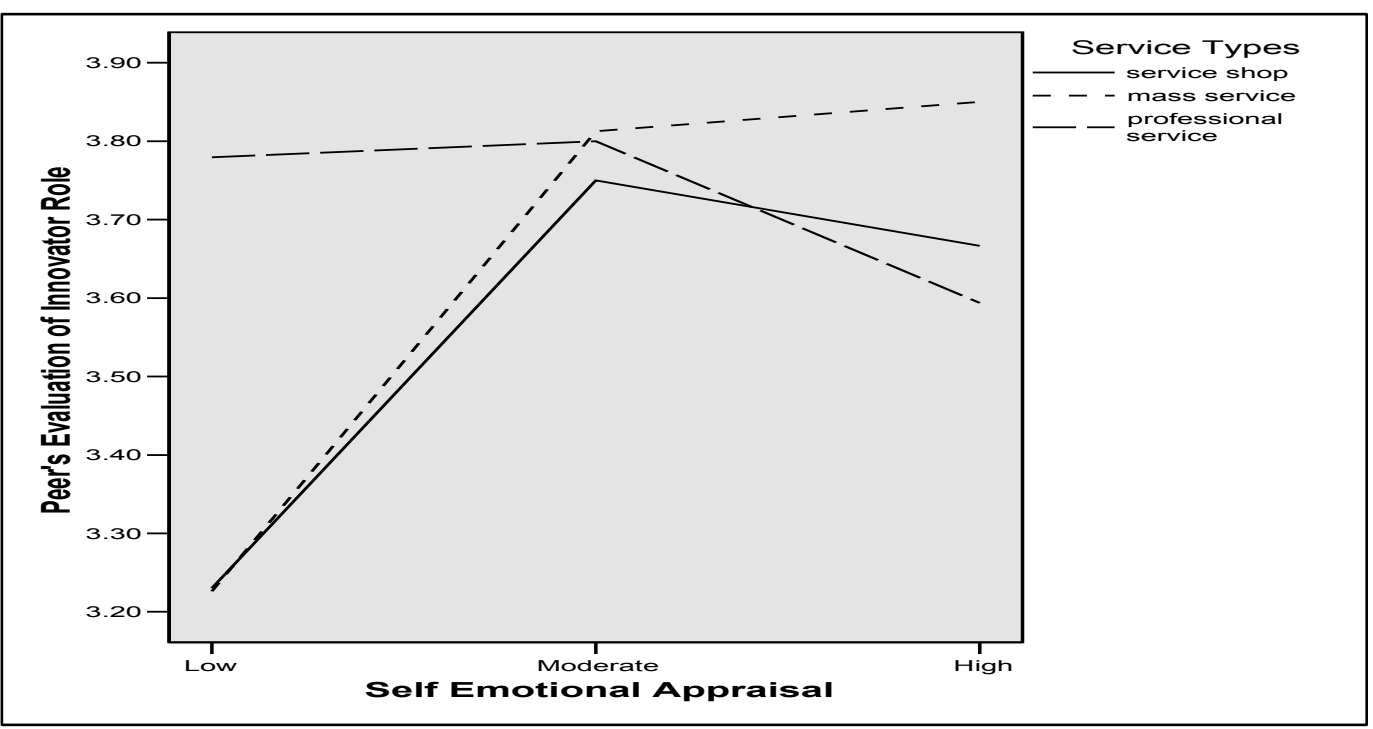

Figure 1. The moderating effect of service types on the relationship between Self Emotional Appraisal and peer's evaluation of innovator role 